\title{
Can joint analysis of postoperative MELD, base excess and blood lactate levels be used as an index of postoperative outcome for patients submitted to liver transplantation? ${ }^{1}$
}

\author{
A análise conjunta do MELD pós-operatório, do base excess e dos níveis séricos \\ de lactato pode ser usada como um índice prognóstico para pacientes \\ submetidos a transplante de fígado?
}

\begin{abstract}
Nathalia Cardoso ${ }^{\mathrm{I}}$, Tiago Silva ${ }^{\mathrm{II}}$, Daniel Cagnolati ${ }^{\mathrm{III}}$, Thiago Freitas ${ }^{\mathrm{III}}$, Enio David Mente ${ }^{\mathrm{IV}}$, Anibal Basile-Filhov, Orlando Castro e Silva $\mathbf{v}^{\mathrm{VI}}$

IUndergraduate Medical student and Monitor of the Digestive Surgery Division, Department of Surgery and Anatomy, of the Faculty of Medicine of Ribeirão Preto, University of São Paulo (FMRP-USP), Ribeirão Preto-SP, Brazil. Acquisition and interpretation of data, responsible for manuscript writing,.

${ }^{I} \mathrm{BS}, \mathrm{PhD}$ Candidate, Teaching assistent, Illinois Institute of Technology, Department of Applied Mathematics, Chicago, Illinois, USA.Statistical analysis and Regression Analysis, Critical Review.

IIIMD, Unit of Liver Transplantation of Department of Surgery and Anatomy of the Faculty of Medicine of Ribeirão Preto, University of São Paulo (FMRP-USP), Ribeirão Preto-SP, Brazil. Critical Review, Technical procedures.

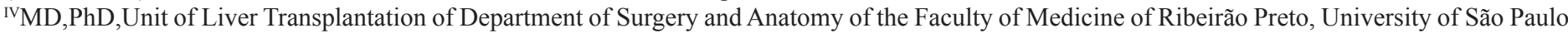
(FMRP-USP), Ribeirão Preto-SP, Brazil. Critical Review.

vMD,PhD Associate Professor, Head of Division of Intensive Care, Department of Surgery and Anatomy, Faculty of Medicine of Ribeirão Preto, University of São Paulo (FMRP-USP), Ribeirão Preto-SP, Brazil. Responsible for intellectual and scientific content of the study.

${ }^{V I} \mathrm{MD}, \mathrm{PhD}$, Full Professor,Chairman and Head of the Department of Surgery and Anatomy, Faculty of Medicine of Ribeirão Preto, University of São Paulo (FMRP-USP), Ribeirão Preto-SP, Brazil. Conception. Designed the protocol; responsible for intellectual and scientific content of the study.
\end{abstract}

\section{ABSTRACT}

PURPOSE: The objective of the present study was to evaluate the postoperative levels of classical or pure MELD and changes in lactate or base excess (BE) levels as possible predictive factors of the type of outcome of patients submitted to orthotopic liver trasplantation (OLT).

METHODS: The study was conducted on 60 patients submitted to OLT at the University Hospital, Faculty of Medicine of Ribeirão Preto, USP, between October 2008 and March 2012. The 30 latest survivor (S) and non-survivor (NS) cases were selected. All liver transplants were performed using the piggy-back technique. ALT, AST, BE and blood lactate values were determined for each group at five time points (immediate preoperative period, end of hypothermal ischemia, 5 and 60 minutes after arterial revascularization and in the immediate postoperative period, when the postoperative MELD was also calculated.

RESULTS: The aminotransferases reached a maximum increase 24 hours after surgery in both the S and NS groups. There was a significantly higher increase in BE and blood lactate in the NS group, especially after 5 minutes of afterial reperfusion of the graft, $\mathrm{p}<0.05$. There was no significant difference in preoperative MELD between groups ( $>0.05$ ), while the postoperative MELD was higher in the NS than in the $\mathrm{S}$ group $(\mathrm{p}<0.05)$

CONCLUSION: Joint analysis of postoperative MELD, BE and blood lactate can be used as an index of severity of the postoperative course of patients submitted to liver transplantation.

Key words: Lactic acid, Liver Transplantation, Severity of Illness Index, Prognosis.

\section{RESUMO}

OBJETIVO: O objetivo do presente estudo é avaliar os níveis do MELD clássico ou puro pós-operatório, alterações dos níveis séricos do lactado e BE, analisando-os como possíveis fatores preditivos do tipo de sobrevida de pacientes submetidos ao transplante ortotópico de fígado (OLT). 
MÉTODOS: Foram analisados 60 pacientes submetidos ao OLT (técnica de piggy-back) no Hospital das Clínicas da Faculdade de Medicina de Ribeirão Preto-USP, entre Outubro 2008 e Março de 2012. Foram selecionados os 30 últimos casos de sobreviventes (S) e 30 de não-sobreviventes (NS). Avaliou-se para cada grupo, os valores ALT, AST, de base excess (BE) e lactato sanguíneos em cinco momentos (pré-operatório imediato, no final da isquemia hipotérmica, 5 e 60 minutos após a revascularização arterial e no pósoperatório imediato, quando também foi calculado o MELD pós-operatório.

RESULTADOS: Com relação às aminotransferases, houve um aumento máximo após 24 horas de pós-operatório em ambos os grupos S e NS. Houve aumento significativo dos níveis de BE e lactato sanguíneo significativamente maior no grupo NS, sobretudo nos tempos após 5 minutos de reperfusão arterial do enxerto, $p<0,05$. Não houve diferença significativa entre o MELD pré-operatório em ambos os grupos ( $p>0,05)$. O MELD pós-operatório foi maior no grupo NS do que no grupo $\mathrm{S}(\mathrm{p}<0,05)$.

CONCLUSÃO: A análise conjunta do MELD pós-operatório, do BE e do lactato sanguíneo pode ser usada como índice de gravidade da evolução pós-operatória de pacientes submetidos ao OLT.

Descritores: Ácido Láctico, Transplante de Fígado, Índice de gravidade de doença, Prognóstico.

\section{Introduction}

Several studies have been conducted to find an ideal parameter that employs clinical symptoms or comorbidities and that can accurately predict postoperative orthotopic liver transplantation (OLT) short-term complications. Among these predictors, Charlson index, APACHE II (Acute Physiology and Chronic Health Evaluation II), Child-Pugh, and post-operative Model for End-stage Liver Disease (MELD) has been proposed to evaluate the early mortality (up to 30 posttransplantation days $)^{1-4}$. Furthermore, other parameters were also utilized such as international normalized ratio (INR) ${ }^{5}$ serial perioperative blood lactate in order to investigate the graft function and its hability to reduce lactate levels after $\mathrm{OLT}^{6-9}$.

However, in situations of hypermetabolism, stress and ischemia such as those occurring during and after OLT, lactate levels increase due to involvement of the organ, with a consequent reduction of lactate clearance and also because the liver becomes an organ producing this substrate ${ }^{10}$. All of this leads to an increase not only in lactate but also in $\mathrm{H}+$, representing metabolic acidosis. The objective of the buffering mechanisms that regulate homeostasis is the maintenance of blood $\mathrm{pH}$ and an important point for this equilibrium occurs at the expense of base consumption. Thus, damage to the organ can be measured or estimated by the equilibrium between lactate and base excess (BE) levels that occur in blood as a mechanism for the maintenance of $\mathrm{pH}$.

In view of the above considerations, the objective of the present study was to evaluate the levels of classical or pure postoperative MELD and the perioperative changes in lactate and $\mathrm{BE}$ levels as possible predictive factors of the type of outcome of patients submitted to OLT.

\section{Methods}

A study was conducted on 60 patients submitted to OLT at the University Hospital, Faculty of Medicine of Ribeirão Preto, USP, from October 2008 to March 2012. The research protocol was approved by the Research Ethics Committee of the Hospital.Among the 106 transplants performed during this period we selected, according to survival up to 30 posttransplantation days, the most recent 30 survivors (A, survivor group) and 30 nonsurvivors (B, nonsurvivor group). All orthotopic liver transplants were performed by the piggy-back technique without a portacaval shunt in an anhepatic phase ${ }^{11}$.

Blood BE and lactate values were determined at five time points (pre-, intra- and immediate postoperative periods) during hospitalization. The intraoperative times included: end of cold ischemia, 5 minutes after arterial revascularization and the first hour after arterial revascularization.

Pre- and postoperative MELD scores were calculated for each group according to the following formula:

\section{MELD $=0.957 \times \log _{\mathrm{e}}($ Creatinine $*)+0.378 \times \log _{\mathrm{e}}($ Bilirubin* $)+$ $1.12 \times \log _{\mathrm{e}}(\mathrm{INR})+\mathbf{0 . 6 4 3}$}

*Creatinine and Bilirubin are expressed in $\mathrm{mg} / \mathrm{dL}$.

The preoperative MELD score considered was that obtained at patient admission on the day of the transplant. For the calculation of postoperative MELD score we used laboratory data obtained up to 6 hours after the end of transplantation.

Statistical analysis

Data are reported as mean $\pm \mathrm{SD}$ or SEM. The 
nonparametric Mann-Whitney test was used to compare differences in demographic and surgical data and in blood ALT and AST concentrations between patients. The capacity of each index to predict the outcome of OLT patients was described by receiver operating characteristic curves (ROC). The area under the ROC curve (AUC) was used as a measure of overall index accuracy and its significance was tested using the Wicoxon test. The serial blood lactate levels (from baseline to D2) were performed by adjusting a random effect model and, the differences between the groups of survivors and nonsurvivors were obtained by orthogonal contrasts, displayed as Log of Lactate, as described previously by Schall ${ }^{12}$. The significance level was set at 0.05 . All statistical analyses were performed using SAS software version 9.2 (SAS Institute Inc., Cary, NC, USA).

\section{Results}

As shown in Table 1, the preoperative MELD score did not differ between the two groups studied ( $>>0.05$ ), whereas the postoperative score differed significantly between survivors and nonsurvivors $(\mathrm{p}<0.05)$. Diuresis during the procedure and times of warm and cold ischemia also did not differ significantly between groups.

TABLE 1 - Demographic, clinical and surgical characteristics of patients submitted to OLT.

\begin{tabular}{lcc}
\hline & $\begin{array}{c}\text { SURVIVORS } \\
(n=30)\end{array}$ & $\begin{array}{c}\text { NONSURVIVORS } \\
(n=30)\end{array}$ \\
\hline Male & 28 & 22 \\
Female & 2 & 8 \\
Age (Years) & $51.6 \pm 12.6$ & $55.0 \pm 9.0$ \\
Pre-OLT MELD & $18.6 \pm 6.4$ & $18.8 \pm 6.6$ \\
$\begin{array}{l}\text { Post-OLT MELD } \\
\text { Time of } \\
\text { hypothermal } \\
\text { ischemia (hours) }\end{array}$ & $22.5 \pm 4.93$ & $26.3 \pm 6.9$ \\
$\begin{array}{l}\text { Time of warm } \\
\text { ischemia (minutes) }\end{array}$ & $72.9 \pm 33.5$ & $8.2 \pm 1.6$ \\
Diuresis (mL) & $1839 \pm 1093$ & $70.5 \pm 38.8$ \\
\hline
\end{tabular}

Aminotransferase levels reached a significant increase $(\mathrm{p}<0.05)$ in non-survivors group at 24 and 48 hours after surgery (Figures 1 and 2)

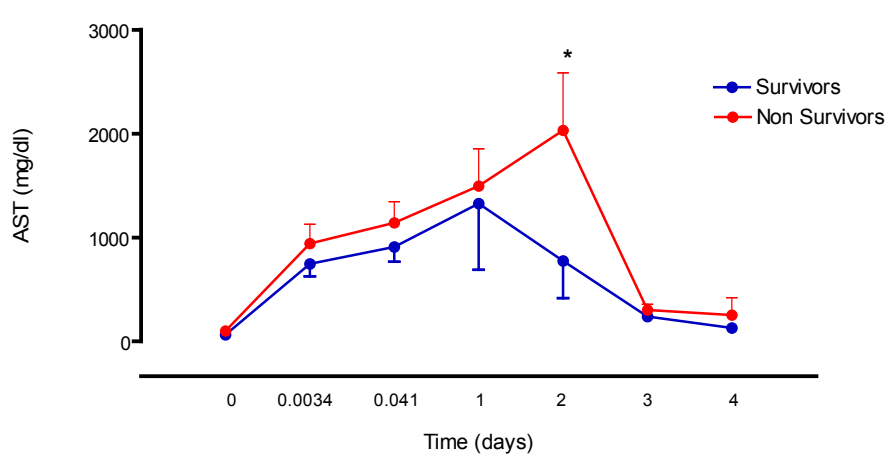

FIGURE 1 - Values of aspartate aminotranferase (AST) of survivors and nonsurvivors at all time points analyzed, reported as mean \pm SEM. $* \mathrm{p}<0.05$.

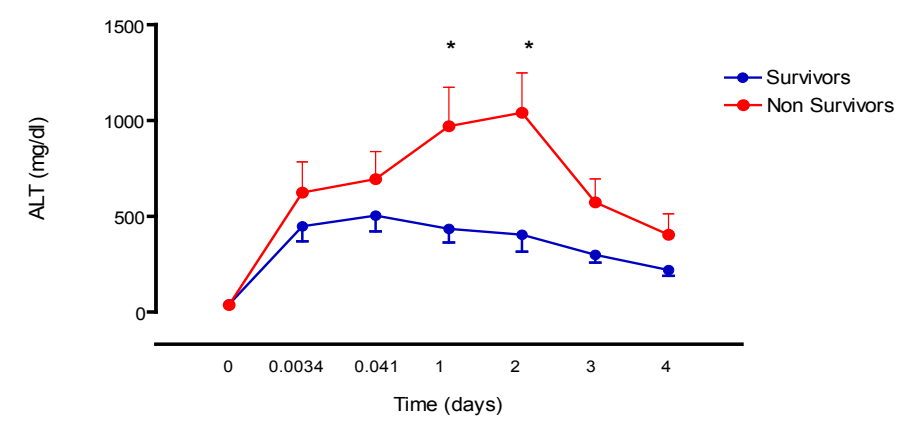

FIGURE 2 - Values of alanine aminotranferase (ALT) of survivors and nonsurvivors at all time points analyzed, reported as mean \pm SEM. * $\mathrm{p}<0.05$.

Lactate levels did not differ significantly between groups $(p>0.05)$ before surgery. However, they differed significantly between groups at the time points chosen, with $\mathrm{p}=0.3$ (CI 0.03 0.61 ) at the end of cold ischemia (before arterial revascularization), $\mathrm{p}=0.02(\mathrm{CI} 0.05-0.69)$ at 5 minutes after revascularization, $\mathrm{p}=$ 0.01 (CI 0.08-0.68) at the first hour after arterial revascularization, and $\mathrm{p}<0.01$ (CI $0.49-1.08$ ) for the postoperative period. The lactate values are shown in Figure 3. 


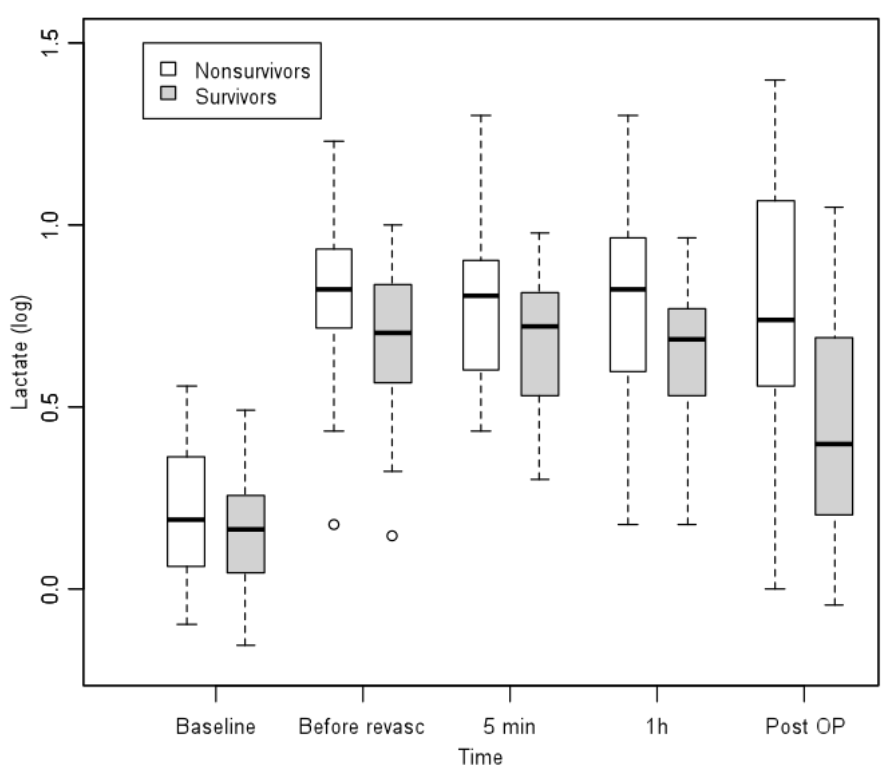

FIGURE 3 - Serial levels of serum lactate represented as log lactate for the survivor and nonsurvivor groups during the immediate preoperative period (baseline), immediately before arterial revascularization, 5 and 60 minutes after arterial revascularization of the graft, and during the immediate postoperative period.

The ROC curve for lactate was $0.55(95 \% \mathrm{CI}=0.40 ; 0.70)$ during the preoperative period; $0.67(95 \% \mathrm{CI}=0.54 ; 0.81)$ at the end of cold ischemia; $0.61(95 \% \mathrm{CI}=0.45 ; 0.78)$ at 5 minutes after arterial revascularization; $0.67(95 \% \mathrm{CI}=0.52 ; 0.81)$ at 1 hour after arterial revascularization, and $0.76(95 \% \mathrm{CI}=0.64 ; 0.88)$ during the postoperative period (Figure 4).

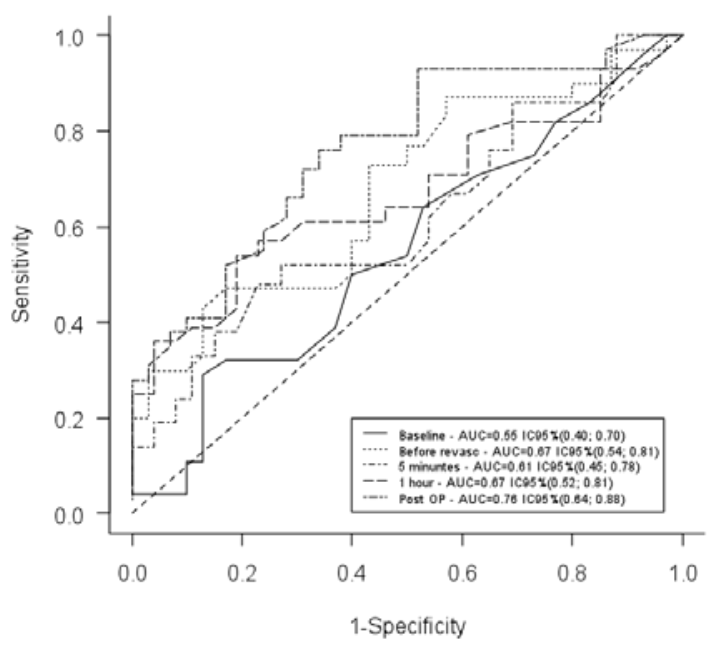

FIGURE 4 - Receiver operating characteristic (ROC) curves for lactate during the immediate preoperative period (baseline), immediately before arterial revascularization, 5 and 60 minutes after arterial revascularization of the graft, and during the immediate postoperative period.

Significant differences between groups were also observed regarding the $\mathrm{BE}$ variable at the surgical time points chosen, with $\mathrm{p}=0.03(95 \% \mathrm{CI} 0.15-2.41)$ at 5 minutes after arterial revascularization, $\mathrm{p}=0.01(95 \% \mathrm{CI} 0.31-2.45)$ for the first hour after arterial revascularization, and $\mathrm{p}<0.01$ (95\%CI $0.34-2.42$ ) for the postoperative period. No difference was observed between groups at the end of cold ischemia (before arterial revascularization) and during the preoperative period $(\mathrm{p}>0.05)$. $\mathrm{BE}$ values $(\log B E 2)$ are presented in Figure 5.

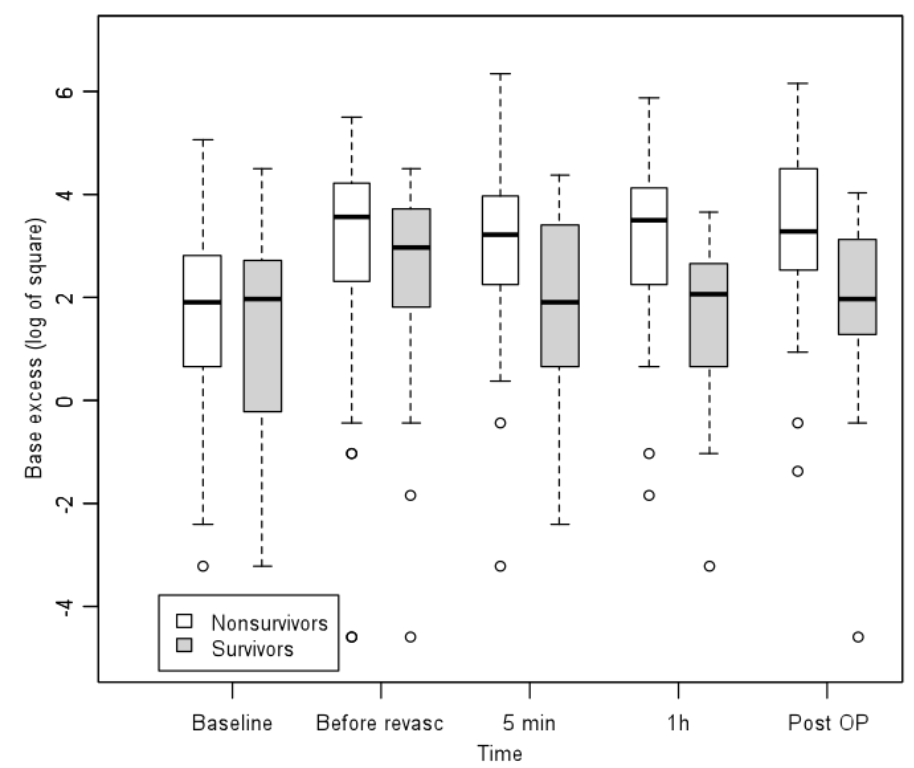

FIGURE 5 - Serial BE levels, presented as $\log B E 2$, of the survivor and nonsurvivor groups during the immediate preoperative period (baseline), immediately before arterial revascularization, 5 and 60 minutes after arterial revascularization of the graft, and during the immediate postoperative period.

The ROC curve was 0.52 for preoperative MELD $(95 \% \mathrm{CI}=0.34 ; 0.68)$ and 0.69 for postoperative MELD $(95 \% \mathrm{CI}=$ $0.56 ; 0.83)$. The result is illustrated in Figure 6.

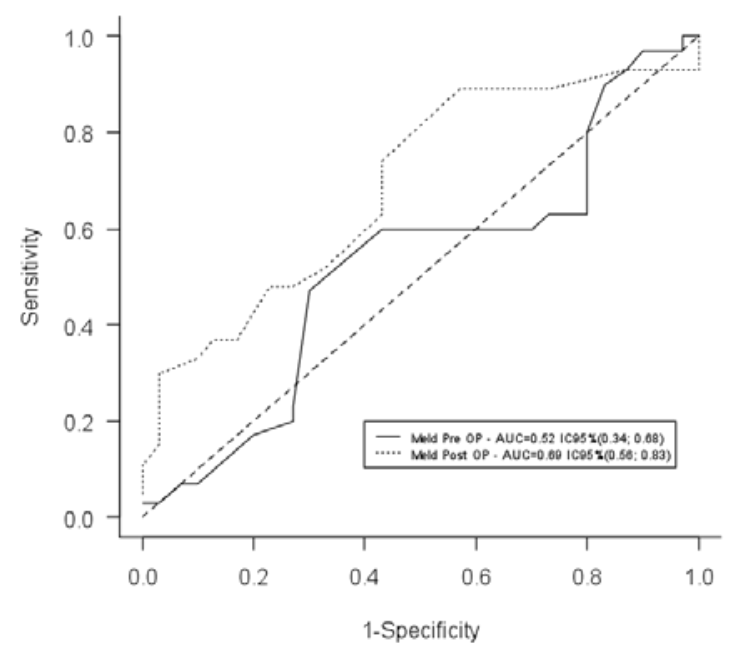

FIGURE 6 - Receiver operating characteristic (ROC) curves for preoperative and postoperative MELD score for the two groups studied. 


\section{Discussion}

Although therapeutic options for end-stage liver disease are limited, it has become clear over the last decade that orthotopic liver transplantation (OLT) is an effective, and often life-saving, intervention for cirrhotic patients, with 5 to $10 \%{ }^{13}$ mortality rates during the first 30 days after surgery and a 5-year survival rate after OLT ranging widely from 65 to $90 \%{ }^{14}$ and appearing to be inversely related to the preoperative values of the Model for End Stage Liver Disease (MELD).

However, the MELD score, introduced in the US in $2002^{15}$ and in Brazil in $2006^{16}$, as an index of hepatic disease severity, has shown serious limitations both as an index to be used for graft allocation and as an indicator of hepatic disease severity and a predictor of early postoperative survival and mortality during the first 30 days after OLT.

The MELD score does not serve all patients well. There are excellent candidates to whom the MELD score does not apply such as patients with hepatocellular carcinoma, refractory ascites, hepatopulmonary syndrome, familial amyloidosis, primary oxaluria, and metabolic disease. In these diseases, the indicators that compose the MELD formula remain invariably unchanged in the short term, coursing with low score values.

In view of these problems, investigations have been conducted over the last five years to find a new way of calculating the MELD. In these studies, new indicators were added to the formula in order to increase the efficacy of the calculation of the severity of liver disease and thus allocate grafts for transplant in a more rational manner. Similarly, an attempt was made to obtain a MELD with a better predictive power of patient outcome after OLT. Based on the somewhat controversial concept that hyponatremia is a sign of higher mortality, sodium was included in the MELD formula. The initial results were also controversial and this addition does not seem to have substantially increased the predictive and allocating power of the MELD formula. Another attempt was to add age to the mathematical calculations of classical MELD (iMELD). Initial studies showed that serum sodium and age were independent predictors of mortality of the MELD score. In a multicenter study, Luca et al. ${ }^{17}$ showed that the iMELD performed better than the original MELD in predicting 3, 6 , and 12-month mortality post liver transplantation.

On the other hand, literature studies have used the classical MELD calculated postoperatively in order to define the type of postoperative course of patients submitted to OLT. Additionally, there are the implications of ischemia and reperfusion (I/R) injury that occurs at varying intensity during $\mathrm{OLT}^{18}$. Also, hepatic changes typical of the donor, such as steatosis of various causes, liver fibrosis and others, not always diagnosed with precision at the time of donor surgery, aggravate the I/R injuries with hepatic, pulmonary and hemodynamic repercussions that may influence the type of outcome of transplanted patients.

Lactate, the final product of glucose degradation in the absence of oxygen, is produced by the reduction of pyruvate. Under normal conditions, the liver and kidneys are great consumers of lactate, being able to utilize as much as $60 \%$ of the lactate available, regulating its cellular levels ${ }^{19-21}$.

Nowadays, orthotopic liver transplantation (OLT) has evolved as an effective therapeutic modality for patients with end-stage chronic liver disease. Early graft function after liver transplantation is an important prognostic marker for the individual outcome. However, liver procurement and implantation are inevitably associated with different degrees of allograft damage due to cold and warm ischemia times, the medical status of the recipient and the surgical complications. Initial poor graft function may be related to the quality of the donor organ and is potentially associated with secondary complications such as renal failure, severe bleeding or septic infections, and might have a negative effect on long-term patient health and employment.

$\mathrm{I} / \mathrm{R}$ disorders caused by reperfusion after implant is the end product that determines the type of postoperative evolution in liver transplantation. The tissue injury occurs as a result of the initial ischemic insult, which is determined primarily by the magnitude and duration of the interruption of the blood supply, and the subsequent damage induced by reperfusion of the new liver in the recipient. The pathologic events induced by $\mathrm{I} / \mathrm{R}$ orchestrate the opening of the mitochondrial permeability transition pore, which appears to represent a common end-effector of the pathologic events iniciated by $\mathrm{I} / \mathrm{R}$.

In the present study, the curves for AST and ALT levels were higher for the nonsurvivor group, although with a significant difference only at 48 hours for AST and at 24 and 48 hours for ALT. At the time points close to implantation and revascularization, although both enzymes increased in both groups, there was no consistent difference between groups. Thus, it can be seen that analysis of the behavior of these enzymes clearly showed the cause-effect relationship between $\mathrm{I} / \mathrm{R}$ injury to the liver graft and increased blood aminotransferase levels occurring in the two groups studied, as reported in the literature ${ }^{22}$. On the basis of this observation, there is no way to predict the type of postoperative course of patients submitted to OLT based on ALT and AST levels.

In the situation of ischemia, stress and hypermetabolism affecting the liver during OLT, lactate increases since its clearance 
is reduced by the transitory impairment of hepatic function due to hypoxia and hypoperfusion. The anaerobic metabolism of glucose produces lactate, ATP and water, with acidosis occurring when ATP is transformed to ADP and inorganic phosphate, a reaction that releases one hydrogen ion. Thus, there is a reduction of blood $\mathrm{pH}$ and the occurrence of metabolic acidosis ${ }^{23}$.

The return of $\mathrm{pH}$ to normal values requires a correction of the processes that produced the disorder and this occurs through three mechanisms: intra- and extracellular buffer, adjustments of $\mathrm{PCO}_{2}$ by respiration, and adjustment of effective renal acid excretion. In the buffer system there is $\mathrm{HCO}_{3-}$ consumption in order to neutralize the increased acid, while for the adjustment of $\mathrm{PCO}_{2}$, there is activation of the bulbar respiratory center which, in an attempt to normalize the $\mathrm{pH}$, courses with hyperventilation, eliminating excess $\mathrm{CO}_{2}$. Finally, the kidneys act on $\mathrm{HCO}_{3-}$ reabsorption and $\mathrm{H}+$ excretion through the nephrons, a fact that also contributes to the return of $\mathrm{pH}$ to normal values. In the present study the ventilation of the patients remained constant, so that it was not a possible error factor when the acid-base balance was analyzed, and the intraoperative diuresis was similar for the survivor and nonsurvivor groups. In addition, the patients of both groups had similar times of cold and warm ischemia ${ }^{23}$.

$\mathrm{BE}$ is equal to the base concentration in blood in $\mathrm{mEq} / \mathrm{L}$, an index that estimates the amount of base necessary for the restoration of normal $\mathrm{pH}$. With the increase in $\mathrm{H}^{+}$in the situation of anaerobiosis, $\mathrm{BE}$ values become more negative, indicating base consumption in order to recover homeostasis.

The important result of the present study was the elevation of lactate to higher levels in the nonsurvivor group, an increase that became significant before arterial revascularization and continued to be significant up to the immediate postoperative period. In contrast, BE levels were found to be different between groups starting at 5 minutes after arterial revascularization, with the difference persisting up to the immediate postoperative period. Taking into account the homeostasis system mentioned earlier, we may consider the increased BE levels to be a response to the metabolic acidosis generated by lactate accumulation in blood, which permitted the maintenance of constant $\mathrm{pH}$ levels in both groups.

Regarding the MELD score, the present study showed the low discriminative power of the pure or classical preoperative MELD for the identification of survivors and nonsurvivors. As reported in the literature, the MELD score does not have high specificity as an index of severity or as a predictor of the type of outcome of transplanted patients. The components used in the formula do not change early enough to interfere with the MELD score during the preoperative period. In contrast, when calculated postoperatively, due to the typical liver changes that occur during the perioperative period, the MELD score has proved to be a better outcome indicator of patients submitted to liver transplantation. Studies aiming to add in some way the BE and/or blood lactate to the MELD components deserve to be considered in the future.

\section{Conclusion}

Joint analysis of postoperative MELD score, excess base and blood lactate can be used as an index of postoperative outcome for patients submitted to liver transplantation.

\section{References}

1. Wasilewicz MP, Raszeja-Wyszomirska J, Wunsch E, Wójcicki M, Milkiewicz P. Modified Charlson comorbidity index in predicting early mortality after liver transplantation. Transplant Proc. 2009;41:3117-8

2. Raszeja-Wyszomirska J, Wasilewicz MP, Wunsch E, Szymanik B, Jarosz K, Wójcicki M, Milkiewicz P. Assessment of a modified Child-Pugh-Turcotte score to predict early mortality after liver transplantation. Transplant Proc. 2009;41:3114-6

3. Knaus WA, Draper EA, Wagner DP, Zimmerman JE. APACHE II: A severity of disease classification system. Crit Care Med. 1985;13:818-29.

4. Basile-Filho A, Nicolini EA, Auxiliadora-Martins M, AlkminTeixeira GC, Martinez EZ, Martins-Filho OA, Castro e Silva O. Comparison of Acute Physiology and Chronic Health Evaluation II death risk, Child-Pugh, Charlson, and Model for End-stage Liver Disease indexes to predict early mortality after liver transplantation. Transplant Proc. 2011;43:1660-4.

5. Shin YH, Yu SK, Kwon CH, Ko JS, Gwak MS, Kim GS. The comparison of the perioperative changes in lactate and prothrombin time between deceased versus living donor liver transplantation. Transplant Proc. 2010;42:4151-3.

6. De Gasperi A, Mazza E, Corti A, Zoppi F, Prosperi M, Fantini G, Scaiola A, Colella G, Amici O, Notaro P, Rocchini A, Ceresa F, Roselli E, Grugni MC. Lactate blood levels in the perioperative period of orthotopic liver transplantation. Int J Clin Lab Res. 1997;27:123-8.

7. Nishimura A, Hakamada K, Narumi S, Totsuka E, Toyoki Y, Ishizawa Y, Umehara M, Yoshida A, Umehara Y, Sasaki M. Intraoperative blood lactate level as an early predictor of initial graft function in human living donor liver transplantation. Transplant Proc. 2004;36:2246-8.

8. Basile-Filho A, Nicolini EA, Auxiliadora-Martins M, Castro e Silva O. The use of perioperative serial blood lactate levels, the APACHE II and the postoperative MELD as predictors of early mortality after liver transplantation. Acta Chir Bras. 2011;26:535-40.

9. Chung IS, Park M, Ko JS, Gwak MS, Kim GS, Lee S.-K. Which Score System Can Best Predict Recipient Outcomes after Living Donor Liver Transplantation? Transplant Proc. 2012;44:393-95.

10. Schroder R, Gumpert JRW, Pluth JR, Eltringham WK, Jenny ME, Zollinger RM Jr. The role of the liver in the development of lactic acidosis in low flow states. Postgrad Med J. 1969;45:566-70.

11. Tzakis A, Todo S, Starzl TW: Orthotopic liver transplantation with preservation of the inferior vena cava. Ann Surg. 1989 210:649-52. 
12. Schall R. Estimation in generalized linear models with random effects, Biometrika. 1991; 78:719-27.

13. Brandman D, Biggins SW, Hameed B, Roberts JP, Terrault NA. Pretransplant severe hepatic encephalopathy, peritransplant sodium and post-liver transplantation morbidity and mortality. Liver Int. 2012; 32:158-64. Epub 2011 Sep 6.

14. Mangus RS, Fridell JA, Vianna RM, Kwo PY, Chen J, Tector AJ. Immunosuppression induction with rabbit anti-thymocyte globulin with or without rituximab in 1000 liver transplant patients with long-term follow-up. Liver Transpl. 2012;18:786-95.

15. Freeman RB: MELD: the holy grail of organ allocation? J Hepatol. 2005;42:16-20.

16. Teixeira AC, Souza FF, Mota GA, Martinelli AL, Sankarankutty AK, Silva OC: Liver transplantation: expectation with MELD score for liver allocation in Brazil. Acta Cir Bras [online]. 2006, 21: suppl.1 12-14.

17. Luca A, Angermayr B, Bertolini G, Koenig F, Vizzini G, Ploner M, Peck Radosavljevic M, Gridelli B, Bosch J. An integrated MELD model including serum sodium and age improves the prediction of early mortality in patients with cirrhosis. Liver Transpl. 2007;13:1174-80.

18. Piratvisuth T, Tredger JM, Hayllar KA, Williams R: Contribution of true cold and rewarming ischemia times to factors determining outcome after orthotopic liver transplantation. Liver Transpl Surg. 1995 1:296-301.

19. Luft FC: Lactic Acidosis Update for Critical Care Clinicians. J Am Soc Nephrol. 200112 Suppl 17:S15-9.

20. Fall PJ, Szerlip HM. Lactic acidosis: from sour milk to septic shock. J Intens Care Med. 2005;20:255-71.

21. Huckabee WE. Abnormal resting blood lactate. II. Lactic acidosis. Am J Med. 1961.30:840-848.

22. Giannini EG, Testa R, Savarino V: Liver enzyme alteration: a guide for clinicians. CMAJ. 2005 1;172:367-79.

23. Kalogeris T, Baines CP, Krens M Korthuis RJ: Cell biology of ischemia/reperfusion injury.Int Rev Mol Biol 2012:229-317.

\section{Correspondence:}

Orlando de Castro e Silva

Av. Bandeirantes, 3900/9 andar

14048-900 Ribeirão Preto - SP Brasil

Tel.: (55 16)3602-2242

orlando@fmrp.usp.br

Conflict of interest: none

Financial source: none

${ }^{1}$ Research performed at Unit of Liver Transplantation, Department of Surgery and Anatomy, Faculty of Medicine of Ribeirao Preto, University of Sao Paulo (FMRP-USP), Brazil. 